\title{
Non-Contractual Liability Arising out of Damage Caused to Another under the DCFR
}

\section{Christian von Bar}

Published online: 14 August 2008

(C) ERA 2008

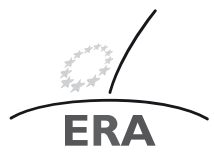

EUROPÄISCHE RECHTSAKADEMIE ACADEMY OF EUROPEAN LAW ACADEMIE DE DROIT EUROPEEN ACADEME DE DROT EUROPEEN TRIER - TREVES - TREVIRI

\section{Non-Contractual obligations in the DCFR}

The DCFR does not just contain model rules on contract law. Whereas Books II and IV have contracts as their sole subject matter, Book III applies, unless otherwise indicated in the relevant section, to both contractual and non-contractual obligations, and Books V, VI and VII are concerned only with non-contractual obligations. The reasons why we dealt with contractual and non-contractual obligations together in Book III are explained in the Introduction to the Interim Outline Edition (at margin no. 48), and I will refer to that text here. The Principles of European Contract Law were not very coherent in this respect. In some areas they went already far beyond contract law, and all that we have done in the DCFR is basically to follow that route and to clarify and extend this approach. There are many areas in which it would have simply made no sense to restrict the relevant model rules to contract law. Think, for example, of the rules on plurality of creditors and debtors, on assignment, on withholding performance and even on performance itself. Article III.-1:102 therefore reads: "This Book applies to obligations within the scope of these rules, whether they are contractual or not, and to corresponding rights to performance." Exceptions to this general rule are clearly indicated, one example being Article III.-3:501 on the scope of the Articles on termination.

It is, however, not just in these areas where we have to be aware of the many overlaps between contractual and non-contractual obligations and their mutual interaction and dependency. Such basic concepts as the notions of damage, loss, economic loss,

Prof. Dr. Dr. h.c. mult. Christian von Bar $(\bowtie)$

European Legal Studies Institute, University of Osnabrück

Heger-Tor-Wall 12, 49069 Osnabrück, Germany

e-mail: Christian.v.bar@uos.de

This article is based on the presentation given by the author at the conference The Draft Common Frame of Reference, organised by ERA in cooperation with the Ministry of Justice of the Republic of Slovenia in the framework of the Slovenian Presidency of the Council of the EU, held in Ljubljana on 28-29 April 2008. 
non-economic loss, negligence, causation, reparation, compensation, contributory fault, exclusion or limitation of liability and so forth are common property of both contract and tort, and as we wished to develop a rule-based list of terminology for European private law it seemed indispensable to cover both areas. It would have been equally inadequate to develop rules on withdrawal, on termination and on avoidance of contracts without a clear picture of all restitutionary instruments, such as unjustified enrichment law, contract law, quasi-contracts and the law relating to the unwinding of void or avoided contracts for services.

\section{The three main non-contractual obligations}

The three main non-contractual obligations dealt with in the DCFR (but certainly not the only ones: see e.g. III.-4:107 [Recourse between solidary debtors]) are the subject matter of Books V, VI and VII. Book V is on benevolent intervention in another's affairs, Book VI on non-contractual liability for damage caused to another, and Book VII on unjustified enrichment law. Of these I will concentrate here on Book VI. The other two subjects were already discussed at earlier ERA conferences, ${ }^{1}$ and it would also simply be too much to address more than one Book in a single introduction.

The DCFR's sixth Book is headed neither "law of delict" nor "tort law". It is headed "Non-contractual liability arising out of damage caused to another". There is, if you like, a complete philosophy behind that title (which, like so many other expressions, we owe Professor Clive). Delict or tort: neither of these terms would have been either appropriate or correct, and the very fact that the Rome II Regulation now uses "delict/tort" (with a stroke in between the two notions) demonstrates once again how urgently we are in need of a proper European legal terminology. The problem with "delict/tort" is not so much the age-old dispute between the continent and the islands (or between Scotland on the one side and England, Ireland and Cyprus on the other). Rather the problem is that both terms would have been wrong (just as, incidentally, they are also wrong in the Rome II Regulation). We have not drafted a mere law of "delict" (which denotes some wrongful conduct); nor have we drafted a set of torts. Instead we have exactly done what we say in our descriptive heading: we have drafted model rules on non-contractual liability arising out of damage caused to another.

\section{The basic approach in Book VI}

Although the two interact, of course, one can distinguish in this area between substance and external presentation (or matters of systematic approach). More than once during these recent years I gained the impression that for academic lawyers the latter (the external presentation) seems to be more important than the former (the substance)! So let me start with the question of how a system of extra-contractual liability could and should look like when drafted in a way that allows for a pan-European discussion of matters of common concern.

1) von Bar [1]; Sprau [2]; Swann [3]; Wendehorst [4]. 
As far as the structure of this area of the law is concerned, basically four groups of countries can be distinguished: the tort based systems of the Common law jurisdictions, the "Romance" families of law with their "general clauses" (in "fault" based liability as well as in "strict" liability), the "Germanic" families of law which rely so heavily on the notion of wrongfulness, and the Nordic countries basing their laws on the culpa rule and on more specific statutory provisions in the area of pure economic loss and interferences with incorporeal rights of personality. It is in these latter two areas where we still deviate from one another to a noticeable extent. The more serious difficulties are in the area of so-called strict liability, however, where the differences are much more pronounced than in the area of so-called fault-based liability.

Against this background we had to find an approach which would allow us to discuss all matters of substance and the pros and cons of the various structures in a way that all of us could accept. The answer to that problem is now set out in VI.-1:101, our "basic rule". It starts from the assumption that each and every claim for reparation requires the presence of three fundamental elements: damage, accountability and causation - no more than that, but equally no less. There are three grounds for being held accountable for a damage caused to another: intention (which is defined in VI.-3:101), negligence (VI.-3:102) and a source of danger specifically addressed in Chapter 3 Section 2 (see VI.-1:101(2)).

In the basic rule we have deliberately avoided the notions of "fault" and "strict liability". Both would have been misleading in our view because negligence does not require fault in a moral sense and also because a liability, once arisen, is always strict in nature. What in common parlance is called a "strict" or "objective" liability is a liability for the causation of damage by others, by things or by animals, i.e. a liability without causation by the defendant personally and, therefore, without the requirement of any conduct (whether correct or wrongful) on his part at all.

VI.-1:101 has some further features which I think should briefly be noted:

- (i) it is deliberately formulated from the point of view of the injured party, rather than the defendant, to underline the fact that reparation for damage is at the heart of this area of the law;

- (ii) it covers both liability based on intention or negligence and liability without intention and negligence;

- (iii) it is drafted in a "unifying" manner, i. e. it is the only basis for a claim existing under Book VI;

- (iv) it contains an indication of the fact that the notion of damage may depend on the ground of accountability (in Chapter 3(2), for instance, it is normally only damage to property [as defined by VI.-2:206] and personal injury [VI.-2:201] which is legally relevant, whereas the notion of legally relevant damage is broader when liability arises under the regime of negligence);

- (v) it uses the notion of reparation as an umbrella term for reparation in kind and compensation, i. e. reparation in money (see VI.-6:101(2)).

As provided for by VI.-1:103(a), however, the basic norm is only applicable in accordance with the following chapters, i. e. the chapters on legally relevant damage, accountability, causation, defences, consequences of liability and on the relationship (of DCFR Book VI) to other areas of the law. The basic rule is not drafted as a selfstanding provision; rather, all its elements are defined in later chapters in a binding manner and must therefore be applied in accordance with the latter. 
Matters of concurrence of actions (and the relationship with contract law in particular) are dealt with by VI.-1:103(c) and (d). We start from the principle of free concurrence of actions, but allow for exceptions where contract law or other areas of the law (e.g. family or property law) so require.

\section{Legally relevant damage}

Chapter 2 is on "legally relevant damage", a new notion that we have also already introduced in the basic rule. We thought that it is not important to know what a damage "is"; it is solely important to know which kinds of detrimental effects generate a right to which kind of legal redress and under which conditions: hence the notion of legally relevant damage. It is impossible to define it once and for all, for all purposes. Sometimes only loss (whether economic and/or non-economic) qualifies as reparable and therefore as legally relevant damage; in other circumstances an injury per se amounts to such a damage; and in yet further cases it is the injury plus the consequential loss.

As a rule we did not make a fundamental distinction between economic and noneconomic loss, nor between economic and pure economic loss. The notion of "pure" economic loss is in itself an extremely difficult one, and it is altogether unknown to many of our jurisdictions. The concept of "injury as such" (or damage per se) has its roots in the Italian danno biologico, but it is now much more widely accepted in Europe - not only, incidentally, in the realm of personal injury, but also in the area of infringements of incorporeal personality rights. It is no doubt a concept which will give rise to much discussion and policy concerns. In the DCFR it is encountered in VI.-2:201(1) and VI.-2:203(1).

Chapter 2 starts with a general definition (in VI.-2:101) of legally relevant damage; the subsequent Articles in its second section describe in a non-exhaustive manner "particular instances of legally relevant damage". These are personal injury, loss suffered by third parties in consequence of another's personal injury or death, infringements of dignity, liberty and privacy, losses upon communication of incorrect information about another, losses upon breach of confidence, infringement of property rights, and reliance on incorrect advice or information, etc. There are not many surprises here, I would think, but I should direct your attention specifically to Articles VI-2:203 (infringements of incorporeal personality rights), 2:205 (which contains the proposal to accept breach of confidence as a distinct source of legally relevant losses), 2:207 (which contains a proposal for a European text on losses in consequence of reliance on incorrect information or advice provided by a person in pursuit of a profession or in the course of trade) and 2:209 (which contemplates a proposal by our French team members on pure ecological damage). Finally, VI.-2:210 (on deceit) and VI.-2:211 (on inducing nonperformance of an obligation) demonstrate once again the close relationship which exists between the notions of (legally relevant) damage and accountability.

\section{The other chapters in overview}

Chapter 3 (on accountability) starts with definitions of intention and negligence. They are followed by rules on the liability of minors and the persons responsible for 
their supervision. As far as parental liability is concerned, we decided, after a long discussion, not to opt for a liability without intention or negligence. We thought that the mere fact that a parent has a child is simply not enough as a ground of accountability in the law on liability for damage. However - and this is a rare exception - we did opt for a solution based on a rebuttable presumption of negligent supervision. The same rule applies in respect of institutions or other bodies obliged to supervise, for example, a mentally disabled person or a dangerous adult. These institutions or bodies may also defend themselves by showing "that there was no defective supervision" (VI.-3:104(3)).

Liability for employees and representatives (VI.-3:201) does not, of course, allow for such an exculpatio. Other instances of liability without intention or negligence concern unsafe immovables (VI.-3:202), animals (VI.-3:203), defective products (VI.-3:204), motor vehicles (VI.-3:205) and dangerous substances and emissions (VI.-3:206). In product liability we propose to deviate from the Directive as far as damage to privately-owned and used property is concerned. We also consider that the exception for damage below the threshold of $€ 500$ should be given up. Finally, VI.-3:207 (Other accountability for the causation of legally relevant damage) is of particular importance. It provides that matters not dealt with in the preceding Articles should be left to national law - or, more precisely, that our model rules also accept liability without intention or negligence where national law (including the law of international conventions binding upon a Member State) so provides.

Chapter 4 (on causation) was deliberately kept short. It contains only three more specific rules (on the egg shell skull principle, on collaborators and on alternative causes), but apart from them we thought that a general formula such as that contained in VI.-4:101(1) suffices. According to this "[g]eneral rule" a person causes legally relevant damage to another if the damage is to be regarded as a consequence of either that person's conduct or a source of danger for which that person is accountable.

Chapter 5 contains a complete list of defences, subdivided into five sections (consent or conduct of the injured person; interests of accountable persons or third persons; inability to control; contractual exclusions and restrictions of liability; and losses within VI.-2:202, i. e. the rule that contributory fault of the primary victim also leads to a reduction of the amount of compensation due to secondary victims). However, the reader should also scrutinise Chapter 7 (Ancillary rules), because one might well also find "hidden" defences in those areas of the law which are listed here because we have not dealt with them (e.g. in labour law with its many restrictions on the personal liability of employees vis-à-vis third parties).

In the rather long sixth chapter we finally deal extensively with remedies. We distinguish here between reparation and prevention (on which see also VI.-1:102) and within reparation between reparation in kind and reparation in money (compensation). The chapter is accordingly subdivided into three sections: reparation in general, compensation, and prevention. Model rules which might be controversial from a policy point of view are contained in VI.-6:101(4) (disgorgement of profits), VI.-6:102 (on trivial damage), VI.-6:202 (allowing for a reduction of liability on equitable grounds) and VI.-6:204 (on compensation for injury as such). Apart from these, Chapter 6 does not, I believe, contain much more than generally (or at least overwhelmingly) accepted principles of modern liability law. 


\section{References}

von Bar, C.: The Principles of European Law on Benevolent Intervention in Another's Affairs and on Unjustified Enrichment. ERA Forum 2, 204 (2006)

Sprau, H.: Benevolent Intervention in Another's Affairs: Some Remarks on the Draft Report Presented by the Study Group on a European Civil Code. ERA Forum 2, 220 (2006)

Swann, S.: A Guide to the Principles of European Law on Unjustified Enrichment. ERA Forum 2, 234 (2006)

Wendehorst, C.: The Draft Principles of European Unjustified Enrichment Law Prepared by the Study Group on a European Civil Code: A Comment. ERA Forum 2, 244 (2006) 